\title{
Espondilodiscitis en hemodiálisis. Papel de enfermería en la sospecha precoz
}

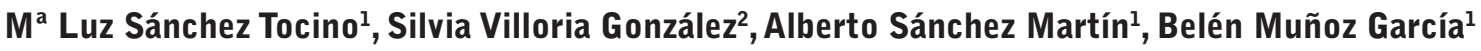 \\ 'Graduado Universitario Enfermería, "Diplomado Universitario Enfermería Centros Hemodiálisis "Las Encinas", \\ Ciudad Rodrigo y "El Castañar", Béjar. Salamanca. Fundación Renal Íñigo Álvarez de Toledo
}

\section{Introducción}

La espondilodiscitis (ED) u osteomielitis vertebral $(O M)$, indica un proceso inflamatorio, generalmente infeccioso, del espacio intervertebral y los cuerpos vertebrales adyacentes ${ }^{1}$. Representa entre un 2 y $7 \%$ de los casos de infección ósea, con una mayor incidencia en adultos entre los 60 y 70 años $2,3,4$.

La infección estafilocócica es muy frecuente en los pacientes en hemodiálisis, siendo la bacteriemia por Staphilococcus aureus una entidad con una morbilidad significativa. El origen más frecuente de dicha bacteriemia son los accesos vasculares permanentes y los catéteres venosos centrales (se calcula que se producen de 1,5 a 5,5 episodios por cada 1000 días/catéter), de los cuales un 1,3\% desarrollarán en algún momento este tipo de infección, si bien la frecuencia es tres veces mayor con el uso de un catéter central que con una fístula arteriovenosa (FAVI) ${ }^{5,6,7}$.

El diagnóstico en multitud de ocasiones es difícil debido a lo inespecífico de sus síntomas y la frecuencia con que se observa dolor de espalda en la población general $^{8}$.

En este artículo presentamos el caso de un paciente con bacteriemia por $S$. aureus que sufrió un absceso vertebral secundario y cuyo síntoma principal fue el dolor de espalda, refiriendo este síntoma a enfermería como primera instancia. Nuestro objetivo es que enfermería

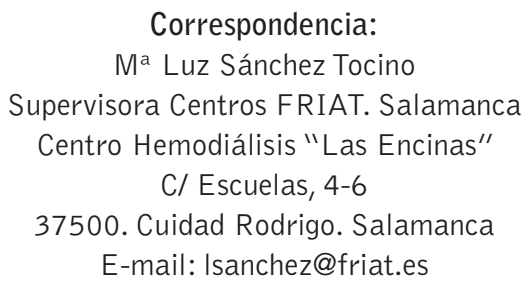

conozca este proceso con el fin de poder identificar los síntomas de un modo precoz.

\section{Caso Clínico}

Varón de 57 años con antecedentes de hipertensión arterial y dislipemia, presenta una cardiopatía isquémica e infarto agudo de miocardio inferior en 2004, arteriopatía periférica con realización de by-pass aorto bifemoral en 2006, sufre en 2010 una isquemia aguda de extremidad inferior izquierda por oclusión de by-pass que requirió revascularización urgente con trombectomia. Se encuentra en programa de hemodiálisis desde Diciembre de 2010 por Insuficiencia renal crónica posiblemente secundaria a nefroangiosclerosis.

Tras fallo de FAVI radiocefálica izquierda se le coloca un catéter temporal yugular izquierdo a finales de agosto de 2013, que es disfuncionante desde el comienzo pero que se mantiene hasta el uso de nueva FAVI húmero cefálica izquierda.

Al mes de colocación del catéter, el paciente refiere de modo puntual a enfermería lumbalgia postural, aunque el propio paciente lo achaca a la realización de algún esfuerzo.

Tras la retirada del catéter (43 días después de inserción), en varias sesiones posteriores presenta malestar general y fiebre, se realiza control bacteriológico del monitor que es negativo y se administra de manera empírica, vancomicina $1 \mathrm{~g}$. junto a un antitérmico, el paciente permanece estable durante el mes siguiente.

Posteriormente, refiere de nuevo dolor lumbar muy intenso que apenas le permite la deambulación, acude a urgencias hasta en cuatro ocasiones en las que tras exploración, radiografía y ecografía abdominal siempre diagnostican lumbalgia mecánica. 
Dado el deterioro del estado general y tras comprobar alteraciones analíticas (aumento proteína $\mathrm{C}$ reactiva y velocidad de sedimentación globular) ingresa en la unidad de medicina interna para estudio. Tras resultados microbiológicos positivos para S. aureus se inicia tratamiento antibiótico dirigido con cloxacilina. Tras la realización de una resonancia nuclear magnética (RNM) se diagnostica una espondilodiscitis D10-D11 que asocia un absceso paravertebral que no condiciona un compromiso de estructuras nerviosas.

Se inicia tratamiento analgésico con fármacos de primer nivel asociados a opiáceos transdérmicos, con titulación progresiva de dosis a lo largo de su estancia hospitalaria y control aceptable del dolor.

El paciente permanece afebril durante todo su ingreso, con disminución progresiva de reactantes de fase aguda y negativización de hemocultivos. Completa cinco semanas de tratamiento antibiótico intravenoso dirigido, pasando a terapia oral ambulatoria y se procede a alta hospitalaria. En estos momentos el paciente permanece estable sin más sintomatología intrahemodiálisis con analgesia controlada por el mismo y a la espera de nueva RNM de control.

\section{Discusión}

La incidencia de espondilodiscitis está creciendo en los últimos años a causa del incremento de la esperanza de vida, al uso de tratamientos de inmunodepresión y en especial al aumento del número de bacteriemias nosocomiales secundarias al uso creciente de dispositivos intravasculares, siendo éstos la primera causa de bacteriemia en pacientes en hemodiálisis ${ }^{1,5,6}$. Según la bibliografía la osteomielitis vertebral es la forma más frecuente de afectación ósea; ocurre con más frecuencia en mayores de 50 años y en varones ${ }^{2,5,6}$, como es nuestro caso. El germen que con más frecuencia se aísla es el S. aureus, causando más del $50 \%$ de los casos. Los pacientes con bacteriemia por $S$. aureus pueden desarrollar complicaciones que suelen ser difíciles de diagnosticar y condicionar minusvalías e incluso la muerte del enfermo ${ }^{6,8}$. La ruta patogénica más común es la diseminación hematógena, favorecida por el sistema de irrigación de la columna vertebral, afectando principalmente a la columna lumbar por su mayor vascularización ${ }^{1,2,5,6}$.

El diagnóstico de la OM suele ser tardío, lo que favorece la diseminación del foco infeccioso, la compresión medular y los déficit neurológicos. El síntoma más frecuente es el dolor de espalda en más del $85 \%$ de los pacientes. Se trata de un dolor insidioso, constante pero inespecífico que empeora progresivamente a

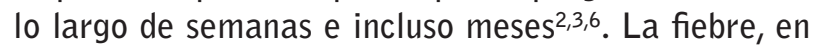
cambio, sólo está presente en un 30-52\% de los enfermos. Otra de las dificultades diagnósticas estriba en que los leucocitos pueden ser normales hasta en el $50 \%$ de los casos $^{2}$. Se suele observar un aumento de los reactantes de fase aguda en un $80 \%$ de los mismos, principalmente la velocidad de sedimentación globular y la proteína $\mathrm{C}$ reactiva. Su descenso progresivo es un excelente marcador de adecuada respuesta al tratamiento $0^{3,5,6,8}$.

En nuestro caso, a pesar de existir en el estadio inicial episodios de febrícula, dolor lumbar y malestar general, no sospechamos de esta patología, a todo esto hay que añadir que además el paciente pasa por un periodo de estabilidad clínica, lo que retrasa aún más la sospecha en el diagnóstico. En quince años de trabajo en nuestros centros no se había dado ningún caso, hicimos muestras a los monitores sospechando contaminación de los mismos e incluso comentamos la posibilidad de que el paciente tuviera alguna tumoración con metástasis lumbar como causa de esta sintomatología. Es tras el gran deterioro del estado general junto con un aumento brusco del dolor lumbar y la aparición de reactantes de fase aguda en su analítica cuando se procede al ingreso para realización de nuevas pruebas diagnósticas.

Menos de un $50 \%$ de pacientes con $0 \mathrm{M}$ vertebral tienen los hemocultivos positivos; sin embargo, deberían sacarse a todos los pacientes con sospecha de ED porque positivos pueden obviar, a veces, la necesidad de procedimientos diagnósticos invasivos ${ }^{6}$. En nuestro caso se identificó el germen en hemocultivo procediéndose al comienzo del tratamiento y dando la pista para la realización de la RNM.

En tercer lugar queremos destacar que los estudios radiográficos y tomográficos (TAC) pueden no ayudar al diagnóstico, en el caso que nos ocupa se realizaron hasta cuatro radiografías que no fueron concluyentes, la destrucción del disco y de los platillos vertebrales adyacentes presente en estos cuadros son hallazgos tardíos a veces difíciles de interpretar ${ }^{2,3,8}$.

La RNM es un estudio de primer orden, muy sensible, específico y precoz, siendo una de las bases del diagnóstico, pero es más costosa y menos accesible ${ }^{2,8}$.

En nuestro caso aun cuando se efectuaron radiografía, ecografía y gammagrafía ósea, es sólo tras la realización de una RNM dorso-lumbar cuando se llega al diagnóstico definitivo de 0M, completándose el tratamiento. 
El tratamiento médico en la mayoría de los casos suele ser conservador, con antibióticos intravenosos entre 4-6 semanas. Posteriormente, se recomienda continuar el tratamiento por vía oral hasta completar 12-24 semanas en función de la evolución clínica y de los marcadores inflamatorios. Es importante la analgesia con opiáceos las primeras semanas y medios ortopédicos para la inmovilización del segmento afectado durante unas 8-12 semanas s,9,10. $^{5}$.

Podemos concluir que el arma terapéutica más eficaz para la OM vertebral y/o absceso epidural es el diagnóstico precoz de estas patologías. Podremos llegar a un diagnóstico precoz siempre que pensemos en estas entidades. Por lo tanto, debemos estar alerta ante un dolor de espalda de reciente aparición en pacientes en hemodiálisis con un episodio reciente de bacteriemia por $S$. aureus, y tener presente que la fiebre no es la regla en este tipo de infecciones.

El papel clásico del personal de enfermería en cualquier tipo de terapia es el de manejar directamente muchos de los tratamientos, controlar las constantes y observar, de forma continuada, la reacción de los pacientes. Enfermería es el primer contacto que el paciente tiene en la sala de hemodiálisis pudiendo ser la primera institución que de la voz de alerta.

La elevada mortalidad derivada de esta patología justificaría plenamente que la realización de una fístula arteriovenosa fuera considerada un procedimiento de urgencia en nuestras instituciones.

Recibido: 2 Agosto 2014

Revisado: 10 Agosto 2014

Modificado: 22 Agosto 2014

Aceptado 23 Agosto 2014

\section{Bibliografía}

1. Fica C Alberto, Bozán P Francisca, Aristegui V Magdalena, Bustos G. Patricio. Espondilodiscitis: Análisis de una serie de 25 casos. Rev. méd. Chile [revista en la Internet]. 2003 Mayo [citado 2014 Feb 17]; 131 ( 5 ): 473-482. Disponible en: <http://www.scielo.cl/scielo.php?script=sci_arttext\&pid=S003498872003000500001\&lng=es.http://dx.doi. org/10.4067/S0034-98872003000500001.>.

2. Arias S, Pérez C, Banchero G, Blanco V, Prado I, Tabárez V. Espondilodiscitis bacterianas inespecíficas. Rev Med Uruguay 2005; 21: 321-326.

3. Pintado-García V. Espondilitis infecciosa. Enferm Infecc Microbiol Clin 2008;26(8):510-7.

4. Rivero MG, Salvatore A, Wouters L. Espondilodiscitis infecciosa espontanea en adultos, análisis de 30 casos. Medicina 1999;59:143- 50.

5. Ramírez $M A$, Sánchez $M D$,Anaya S,Arambarri M,Caparrós G, Rivera F, Romera A, M. Vozmediano $M C$, Ferreras I. Espondilodiscitis, experiencia en nefrología. Nefrologia 2013;33(2):xx

6. Valero $R$, Castañeda 0, de Francisco AL, Piñera $C$, Rodrigo E, Arias M. Casos Clínicos: Sospecha clínica de osteomielitis vertebral: dolor de espalda en los pacientes con infección asociada a catéter de hemodiálisis. Nefrología 2004;6:583-8.

7. Gándara $M$, Cuadrado $M^{a} E$, Sainz RA, Sánchez $S$, Cepa H, Peiro S, Vicente Y, Diez M, Alonso R. El acceso vascular: Primera preocupación de Enfermería. Disponible en: <http://www.revistaseden. org/files/2052_113\%5B2\%5D.pdf>

8. Belzunegui J. Espondilodiscitis infecciosa. Reumatol Clin. 2008;4 Supl 3:13-7

9. Aguinaga A, Del Pozo JL. Infección asociada a catéteres en hemodiálisis: diagnóstico tratamiento y prevención. Nefroplus 2011, 4(2): 1-10.

10. Gómez N. Espondilodiscitis infecciosas. En: Cañete J, Gómez-Reino J, González-Gay M, Herrero-Beaumont G, Morillas L, Pablos J, et al. (eds.). Manual SER de las enfermedades reumáticas. Madrid: Médica Panamericana; 2008. p. 359-62. 